\title{
Are there increased periprocedural complications with the MRI-conditional Medtronic Revo SureScan Pacing System?
}

\section{A meta-analysis}

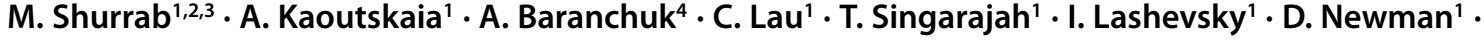 \\ J. S. Healey 5 E. Crystal'1,2 \\ Published online: 6 February 2018 \\ (c) The Author(s) 2018. This article is an open access publication.
}

\begin{abstract}
Background The use of magnetic resonance imaging (MRI)-conditional permanent pacemakers has increased significantly. In this meta-analysis, we examine the safety of MRI-conditional pacing systems in comparison with conventional systems. Methods An electronic search was performed using major databases, including studies that compared the outcomes of interest between patients receiving MRI-conditional pacemakers (MRI group) versus conventional pacemakers (control group).

Results Six studies ( 5 retrospective and 1 prospective non-randomised) involving 2,118 adult patients were identified. The MRI-conditional pacemakers, deployed in 969 patients, were all from a single manufacturer (Medtronic Pacing System with 5086 leads). The rate of pacemaker lead dislodgement (atrial and ventricular) was significantly higher in the MRI group (3\% vs. 1\%, OR $2.47(95 \%$ CI 1.26; 4.83), $p=0.008)$. The MRI group had a significantly higher rate of pericardial complications $(2 \%$ vs. $1 \%$, OR $4.23(95 \%$ CI $1.18 ; 15.10), p=0.03)$ and a numerically higher overall complication rate in comparison with the conventional group (6\% vs. 3\%, OR $2.02(95 \%$ CI $0.88 ; 4.66), p=0.10)$ but this was not statistically significant.

Conclusions In this meta-analysis, the rates of pacemaker lead dislodgement and pericardial complications were significantly higher with the Medtronic MRI-conditional pacing system.
\end{abstract}

Keywords Pacemakers $\cdot$ MRI $\cdot$ Complications $\cdot$ meta-analysis

\section{Introduction}

M. Shurrab

shurrabm@hotmail.com

1 Arrhythmia Services, Schulich Heart Centre, Sunnybrook Health Sciences Centre, University of Toronto, Toronto, Ontario, Canada

2 Division of Cardiology, Women's College Hospital, University of Toronto, Toronto, Ontario, Canada

3 Institute of Health Policy, Management and Evaluation, University of Toronto, Toronto, Ontario, Canada

4 Division of Cardiology, Kingston General Hospital, Queen's University, Kingston, Ontario, Canada

5 Population Health Research Institute, McMaster University, Hamilton, Ontario, Canada
There is a worldwide steady and growing use of permanent pacemakers (PPMs); every year 600,000 PPMs are implanted and this number is increasing [1]. Interestingly, $50-75 \%$ of patients with a PPM may have an indication for MRI scanning during their lifetime, which urged the development of MRI-compatible PPM [2]. In 2011, the US Food and Drug Administration approved the first MRI-conditional pacing system in the United States: the Medtronic Revo SureScan Pacing System, the Generator and two CapSureFix MRI 5086 active-fixation pacing leads. To minimise the effects of the magnetic field, multiple design changes have been incorporated, which led to a stiffer lead that transfers more torque than other modern active fixation leads [3]. Many trials have confirmed the safety of performing MRI scanning on patients with these devices but very 
few looked at the safety of implantations and outcomes of the actual procedures $[4,5]$. We thus conducted a meta-analysis to examine specifically the safety of MRI-conditional pacing systems in comparison with conventional systems.

\section{Methods}

\section{Literature search and data sources}

An electronic literature search was performed by two investigators (MS, AK) using PubMed until 28 August 2017. The search terms were: pacemaker AND magnetic resonance imaging. Neither language nor demographic restrictions were applied. All references from papers obtained through the database were reviewed manually. In addition, we performed a manual web search looking at different manufacturers' databases as well as conference websites and proceedings. We only included full papers and excluded reports that did not provide full data about the outcomes of interest. The electronic search has been archived and is available upon request.

\section{Study selection and quality assessment}

The inclusion was limited to studies which:

1. compared the outcomes of interest between patients receiving MRI-conditional PPMs (MRI group) versus conventional PPMs (control group);

2 . included an adult population $>18$ years old; and

3. provided comprehensive data on outcomes of interest.

The selection of studies was assessed independently by three assessors (MS, AK, TS). We excluded non-comparative trials, crossover studies, case reports, editorials, letters, replies, and reviews.

\section{Data extraction}

Three reviewers (MS, AK, TS) independently extracted the data from published sources; disagreements were resolved by discussion and, when necessary, in consultation with other co-authors.

Outcomes of interest were:

1. The rate of pacemaker lead dislodgement (atrial and ventricular);

2. pericardial complications (including pericarditis, pericardial effusion and cardiac tamponade);

3. overall complications; and

4. pacemaker parameters including sensing and pacing thresholds and impedance.
Whenever possible, direct communication with the authors of the papers was undertaken in an attempt to obtain the data of interest if presentation in the manuscript was incomplete.

We used the Newcastle-Ottawa Scale to further assess the quality of the observational studies. Studies were judged on three broad perspectives:

1. selection of the study groups;

2. comparability of the groups; and

3 . ascertainment of either the exposure or outcomes of interest for case-control or cohort studies, respectively [6].

\section{Statistics}

The software package RevMan (version 5), provided by the Cochrane Collaboration, was used for combining outcomes from the individual studies and statistical analysis. Outcomes were pooled using a random-effects model described by DerSimonian and Laird [7]. Summary estimates and $95 \%$ confidence intervals (CIs) were reported for dichotomous variables as odds ratio (OR). The heterogeneity between studies was assessed using Cochrane's $X^{2}$ and $I^{2}$. An $I^{2}>50 \%$ was considered to represent significant heterogeneity [8]. Statistical significance was set at $p<0.05$. We calculated the weighted means for the variable baseline characteristics and complication outcomes whenever possible. Otherwise we captured the medians with range or interquartile range as reported in the individual studies.

\section{Results}

\section{Summary of the studies}

The literature search resulted in 1,204 studies (1,129 from electronic databases and 75 from other resources including web searches and reference lists). We identified six studies ( 5 retrospective and 1 prospective non-randomised) that met all the inclusion criteria of this meta-analysis [3, 9-13]. The information relevant to the literature search is shown in Fig. 1. All studies that met our inclusion criteria used the Medtronic Revo SureScan Pacing System (with Medtronic CapSureFix 5086 leads) as the MRI-conditional pacing system. Different pacing systems were used in the control group. Tab. 1 presents a summary of the included studies, the pacing systems used, and the follow-up periods in the individual studies.

\section{Baseline characteristics of patients}

In total, 2,118 patients were included in this study. Medtronic MRI-conditional Revo SureScan Pacing Sys- 
Fig. 1 Flow diagram of literature search and study selection
1129 records identified through literature searching via electronic database (PubMed)
75 studies obtained from other resources including manual web searches, reference lists, and review articles

Total of 1204 potentially relevant studies identified through literature search and screened

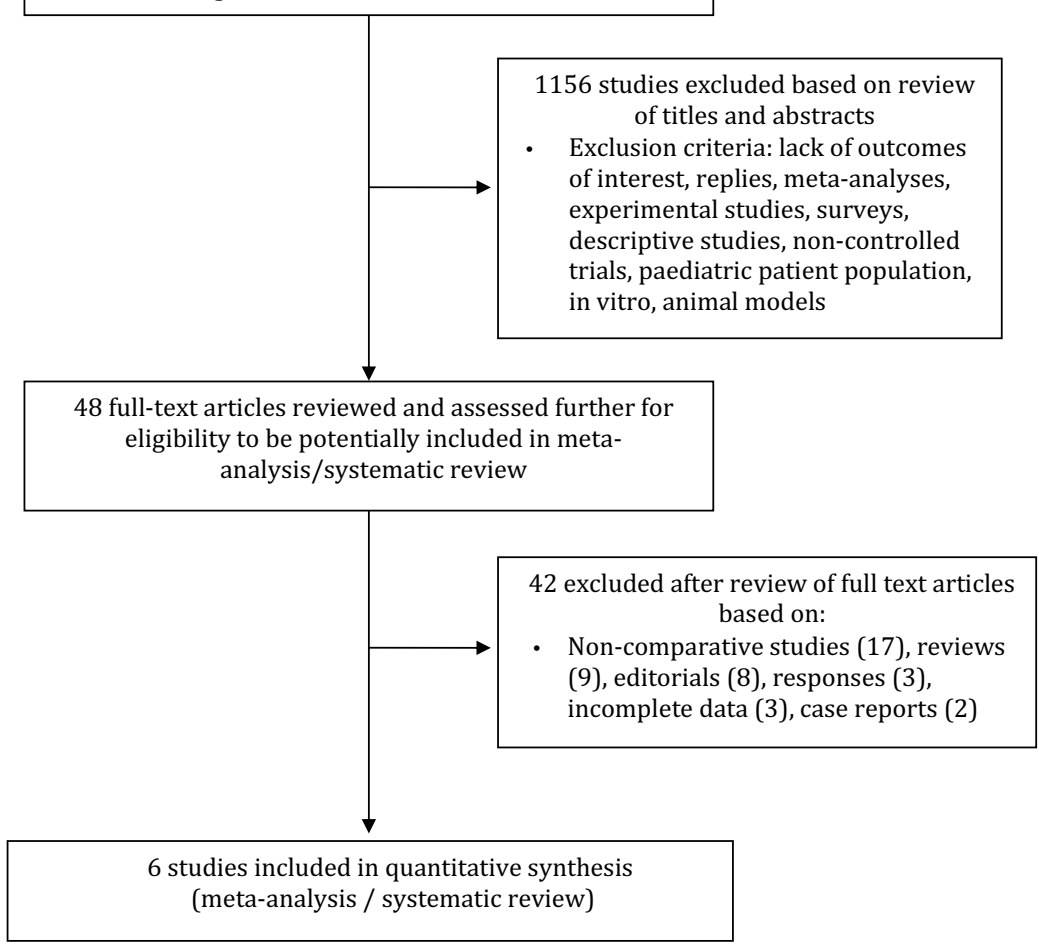

Table 1 Summary of included studies

\begin{tabular}{|c|c|c|c|c|c|c|}
\hline \multirow{2}{*}{$\begin{array}{l}\text { Study/Year } \\
(n=5)\end{array}$} & \multirow[t]{2}{*}{ Type of Study } & \multicolumn{2}{|c|}{ No. of patients } & \multicolumn{2}{|l|}{ Type of Lead } & \multirow{2}{*}{$\begin{array}{l}\text { Follow-up } \\
\text { (Months) }\end{array}$} \\
\hline & & $\begin{array}{l}\text { MRI } \\
(n=969)\end{array}$ & $\begin{array}{l}\text { Control } \\
(n=1,149)\end{array}$ & MRI & Control & \\
\hline $\begin{array}{l}\text { Forleo } 2010 \\
{[10]}\end{array}$ & $\begin{array}{l}\text { Prospective, non-ran- } \\
\text { domised, controlled } \\
\text { study }\end{array}$ & 50 & 57 & $\begin{array}{l}\text { Medtronic CapSureFix } \\
5086 \text { MRI SureScan }\end{array}$ & $\begin{array}{l}\text { Medtronic CapSureFix } \\
\text { Novus } 4076\end{array}$ & 12 \\
\hline $\begin{array}{l}\text { Wollmann } \\
2011[12]\end{array}$ & Retrospective study & 39 & 59 & $\begin{array}{l}\text { Medtronic CapSureFix } \\
5086 \text { MRI SureScan }\end{array}$ & $\begin{array}{l}\text { Medtronic } 4592 \text { (atrial } \\
\text { leads); } 4092 \text { (ventricu- } \\
\text { lar leads) }\end{array}$ & $6.5 \pm 2.75^{\mathrm{a}}$ \\
\hline $\begin{array}{l}\text { Elmouchi } \\
2014[3]\end{array}$ & $\begin{array}{l}\text { Retrospective case-con- } \\
\text { trol study }\end{array}$ & 65 & 92 & $\begin{array}{l}\text { Medtronic CapSureFix } \\
5086 \text { MRI SureScan }\end{array}$ & $\begin{array}{l}\text { Medtronic CapSureFix } \\
\text { Novus } 5076\end{array}$ & 14 \\
\hline $\begin{array}{l}\text { Rickard } 2014 \\
{[11]}\end{array}$ & $\begin{array}{l}\text { Retrospective cohort } \\
\text { study }\end{array}$ & 466 & 316 & $\begin{array}{l}\text { Medtronic CapSureFix } \\
5086 \text { MRI SureScan }\end{array}$ & $\begin{array}{l}\text { Medtronic } 5076 \text { and } \\
\text { Medtronic } 4193 \text { (left } \\
\text { ventricular leads) }\end{array}$ & $\begin{array}{l}25.5^{\mathrm{b}} \\
44.3^{\mathrm{c}}\end{array}$ \\
\hline Acha 2015 [9] & $\begin{array}{l}\text { Retrospective, non-ran- } \\
\text { domised, case-series } \\
\text { study }\end{array}$ & 72 & 420 & $\begin{array}{l}\text { Medtronic CapSureFix } \\
5086 \text { MRI SureScan }\end{array}$ & $\begin{array}{l}\text { CapSureFix Novus } \\
4076 \text { and } 5076\end{array}$ & 34 \\
\hline $\begin{array}{l}\text { Kwon } 2016 \\
{[13]}\end{array}$ & Retrospective study & 277 & 205 & $\begin{array}{l}\text { Medtronic CapSureFix } \\
5086 \text { MRI SureScan }\end{array}$ & $\begin{array}{l}\text { Medtronic CapSureFix } \\
\text { Novus } 5076\end{array}$ & 1 \\
\hline
\end{tabular}

${ }^{\mathrm{a}}$ Mean \pm standard deviation

${ }^{\mathrm{b}}$ Control group

${ }^{\mathrm{c} M R I}$ group 
Table 2 Patient baseline characteristics

\begin{tabular}{lccl}
\hline Variable & MRI & Control & $P$-value \\
\hline $\begin{array}{l}\text { Total patients (no.) } \\
\begin{array}{l}\text { Age (years) } \\
\text { (mean } \pm \text { SD) }\end{array}\end{array}$ & 969 & 1,149 & $n / \mathrm{a}$ \\
$\begin{array}{l}\text { Male gender } \\
\begin{array}{l}\text { History of atrial ar- } \\
\text { rhythmias }\end{array}\end{array}$ & $58 \%$ & $72 \pm 4.89$ & 0.109 \\
$\begin{array}{l}\text { Hypertension } \\
\begin{array}{l}\text { Left ventricular ejec- } \\
\text { tion fraction }\end{array}\end{array}$ & $55 \%$ & $55 \%$ & 0.635 \\
\hline
\end{tabular}

$n / a$ not applicable tems with 5086 leads (MRI group) were used in 969 patients. Baseline demographics and clinical characteristics were similar between the MRI and control group (age: $68 \pm 2.4$ vs. $72 \pm 4.9$ years, $p=0.11$; male gender: $58 \%$ vs. $55 \%, p=0.64$; history of atrial arrhythmias: $39 \%$ vs. $29 \%$, $p=0.43$; hypertension: $55 \%$ vs. $62 \%, p=0.97$; and left ventricular ejection fraction: $60 \pm 1.99$ vs. $60 \pm 3.70, p=0.60$ ). A summary of the baseline characteristics is presented in Tab. 2 .

(

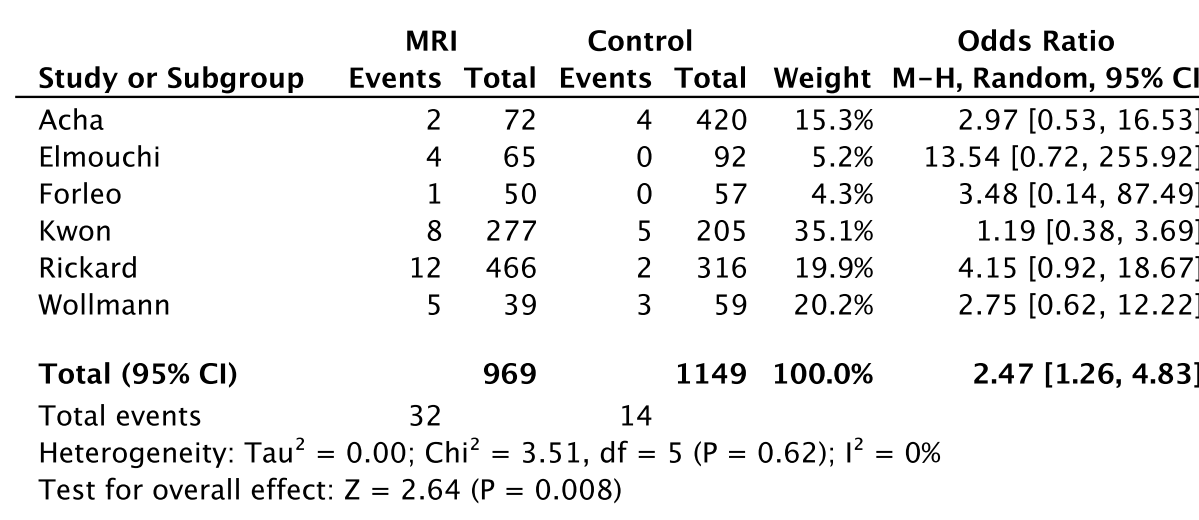

Fig. 2 Forest plot of the individual and combined rates of atrial and ventricular lead dislodgements

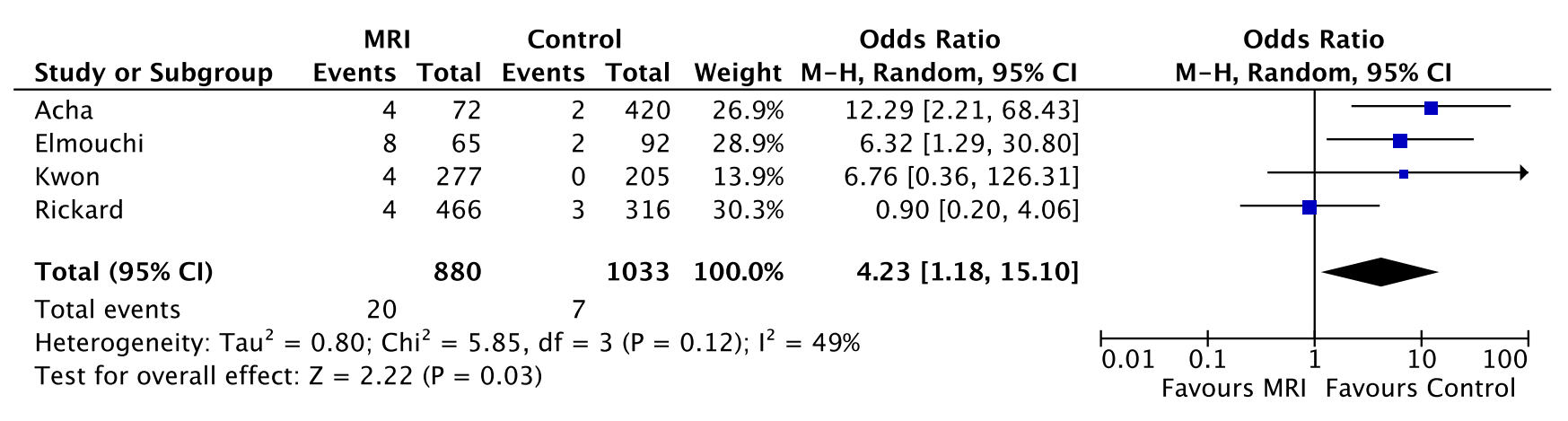

Fig. 3 Forest plot of the individual and combined rates of pericardial complications

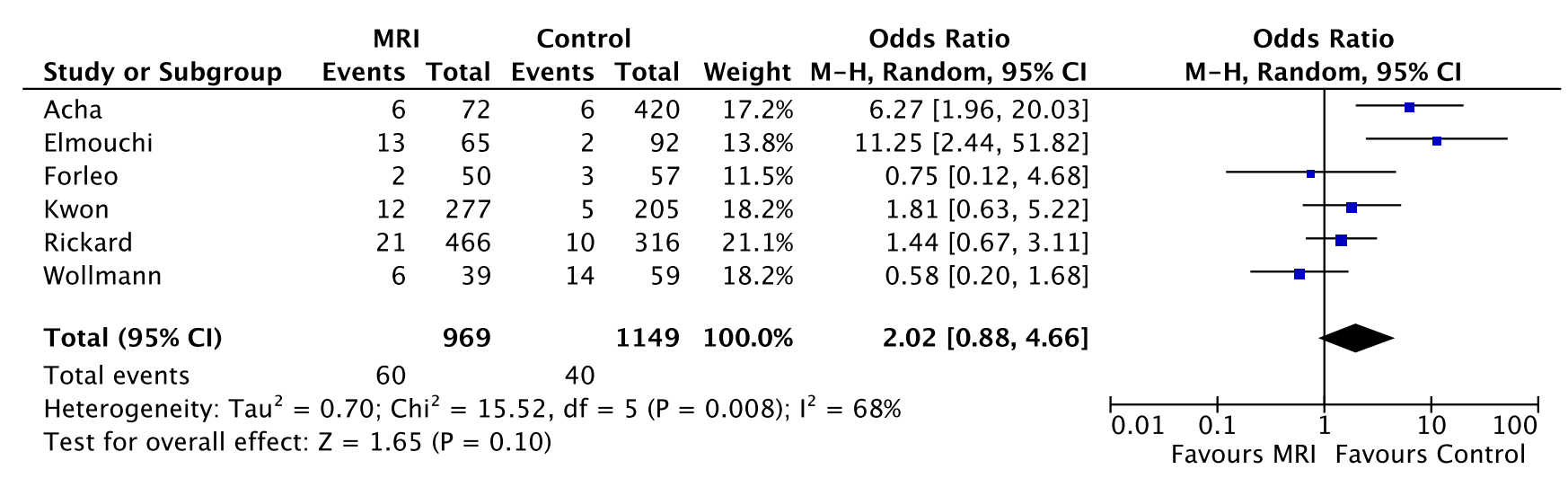

Fig. 4 Forest plot of the individual and combined rates of overall complications 
Table 3 Comparison of outcomes

\begin{tabular}{llll}
\hline & MRI in $\%$ & Control in $\%$ & $P$-value \\
\hline Total complications & 6.19 & 3.48 & 0.100 \\
Pericardial complications $^{\mathrm{a}}$ & 2.27 & 0.68 & 0.030 \\
Total leads dislodgement & 3.30 & 1.22 & 0.008 \\
\hline
\end{tabular}

Mean calculated as weighted mean

aPericardial complications: pericarditis, pericardial effusion, cardiac tamponade

Table 4 Lead parameters

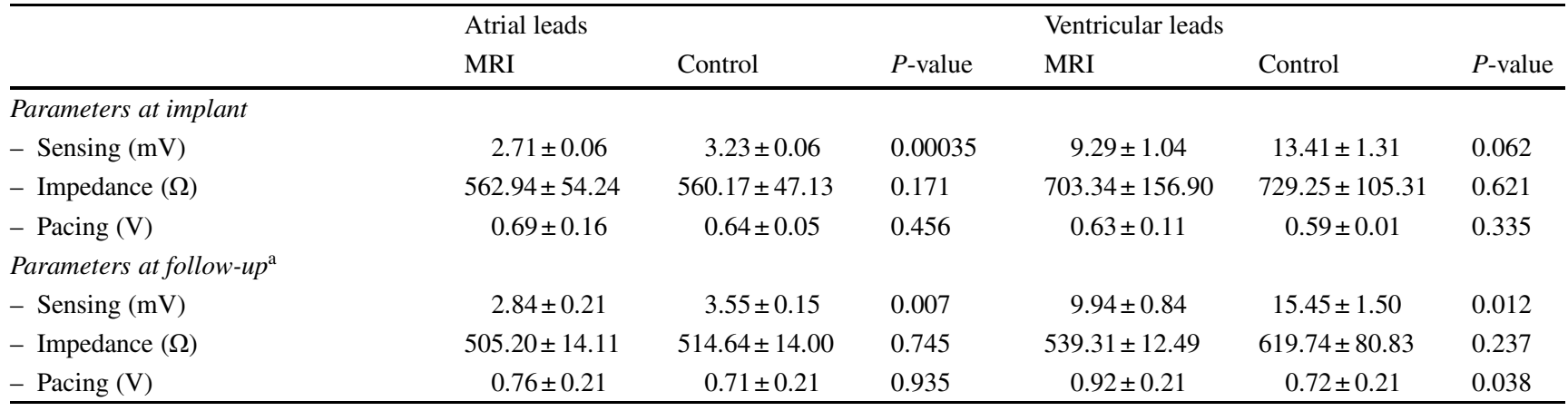

Mean calculated as weighted mean \pm standard deviation

${ }^{a}$ Follow-up range between 6 weeks and 12 months

\section{Outcomes of interest}

The rate of pacemaker lead dislodgement (atrial and ventricular) was significantly higher in the MRI group (3\% vs. $1 \%$, OR 2.47 (95\% CI 1.26; 4.83), $p=0.008)$. No significant heterogeneity was noted for this comparison $\left(I^{2}=0 \%\right.$, $p=0.62$ ) (Fig. 2).

All studies reported the overall complication rate. The MRI group had a significantly higher rate of pericardial complications ( $2 \%$ vs. $1 \%$, OR 4.23 (95\% CI $1.18 ; 15.10)$, $p=0.03$ ) and a numerically higher overall complication rate in comparison with the control group ( $6 \%$ vs. $3 \%$, OR 2.02 (95\% CI $0.88 ; 4.66), p=0.10$ ) but was not statistically significant, as shown in Figs. 3 and 4 respectively. Tab. 3 shows the rates of different individual complications.

Sensing parameters of atrial and ventricular leads immediately postoperatively and at follow-up (ranges between 6 weeks and 12 months) were significantly lower in the MRI group. In fact, ventricular lead pacing thresholds were significantly higher in the MRI group at follow up. Tab. 4 shows all the lead parameters postoperatively and at followup.

\section{Discussion}

Our meta-analysis has demonstrated the following main findings: The rate of pacemaker lead dislodgement (atrial and ventricular) was significantly higher with the use of Medtronic MRI-conditional Revo SureScan Pacing Systems with 5086 leads, with a significantly higher rate of pericar- dial complications and numerically higher overall complications in comparison with the conventional group.

Many reports have focused on the feasibility and safety of performing MRI scanning on patients with these devices but very few studies have looked at the safety and outcomes of the actual procedures [4, 5]. Although the studies included in our meta-analysis showed consistently higher complication rates, specifically the rate of pericardial complications with the Medtronic MRI-conditional Revo SureScan Pacing Systems with 5086 leads, two large randomised trials have shown a slightly lower (but likely not significant) rate of pericardial complications. In the EnRhythm MRI Study [14] and the Advisa MRI Study [15], there was $1-2 \%$ rate of perforation and/or pericardial effusion. Both studies represent specific clinical studies that follow unique, extensive protocols and implanting techniques. This includes pre-implant helix extension and retraction, using slower pin rotations, avoiding driving the lead with a fully seated stylet and avoiding the reverse 'helicoptering' of the 'pinch-on' tool once the helix is extended [3,9]. Our metaanalysis represents rather more real-world procedural outcomes that reflect a wide variety of clinical practice.

Although the 5086 lead is a fairly new pacing lead, the outcomes of our study showing a lower safety profile for MRI-conditional PPMs are unlikely to be solely due to the learning curve of implanting physicians with this relatively new technology [16]. There are many specific design changes incorporated into the leads, including decreasing the number of filars and increasing diameter, increasing the number of turns in the inner coil and increasing the outer lead diameter [3]. As a result of these changes, the MRI 
lead is thicker, stiffer and transfers more torque. Sensing parameters of atrial and ventricular leads immediately postoperatively and at follow-up were significantly lower in the MRI group. Also, ventricular lead pacing thresholds were significantly higher in the MRI group at follow-up. While technically (statistically) true, it is unlikely that any of those differences would lead to any meaningful clinical outcome such as under sensing or battery longevity issues.

Three Medtronic leads (5076, 4074 and 4574) have been recently approved for use in the MRI environment and they are smaller in size in comparison with MRI-conditional leads with long-term implanting experience. Hence it is expected that these newly approved MRI-compatible pacing systems will have a wider usage and favourable outcomes, replacing the 5086 pacing leads in the near future. Moreover, other manufacturers have recently introduced MRIconditional pacing systems; however, more reports are required to assess their safety.

\section{Limitations}

Some studies were of limited quality given their retrospective nature and single-centre design. The results of our meta-analysis are based on the use of only a specific MRIcompatible lead, and cannot be generalised to all MRIcompatible systems. The discrepancy in follow-up periods among the studies could affect the outcomes. Assessing outcomes such as the complication rate is rather complex and multifactorial. Factors such as different levels of overall and system-specific experience among operators may alter our conclusions. The limited number of articles to be adopted, the small number of events and the short observation period are significant limitations of this meta-analysis. There could have been a lack of statistical power for some outcomes. Analysis related to some of the outcomes showed significant heterogeneity such as overall complications. Nevertheless outcomes such as lead dislodgements had insignificant heterogeneity that could reflect some similarities among studies.

\section{Conclusion}

This meta-analysis supports the safety of conventional PPMs in comparison with the Medtronic MRI-conditional Revo SureScan Pacing Systems with 5086 leads. The rate of pacemaker lead dislodgement was significantly higher in the MRI group. In addition, there were significantly more pericardial complications and a numerically higher overall complication rate in comparison with the conventional group.

\section{Abstract presentation}

Is there an increased complication rate with MRI-compatible PPM in comparison to conventional PPM? A metaanalysis. Heart Rhythm, Vol. 13, No. 5, May Supplement 2016.

Conflict of interest J.S. Healey: Research grant from Medtronic. E. Crystal: Research grant from Biotronik. M. Shurrab, A. Kaoutskaia, A. Baranchuk, C. Lau, T. Singarajah, I. Lashevsky and D. Newman declare that they have no competing interests.

Open Access This article is distributed under the terms of the Creative Commons Attribution 4.0 International License (http:// creativecommons.org/licenses/by/4.0/), which permits unrestricted use, distribution, and reproduction in any medium, provided you give appropriate credit to the original author(s) and the source, provide a link to the Creative Commons license, and indicate if changes were made.

\section{References}

1. Wood MA, Ellenbogen KA. Cardiology patient pages. Cardiac pacemakers from the patient's perspective. Circulation. 2002;105: 2136-8.

2. Nazarian S, Halperin HR. How to perform magnetic resonance imaging on patients with implantable cardiac arrhythmia devices. Heart Rhythm. 2009;6:138-43.

3. Elmouchi DA, Rosema S, Vanoosterhout SM, et al. Cardiac perforation and lead dislodgement after implantation of a MR-conditional pacing lead: a single-center experience. Pacing Clin Electrophysiol. 2014;37:4-10.

4. Nordbeck P, Ertl G, Ritter O. Magnetic resonance imaging safety in pacemaker and implantable cardioverter defibrillator patients: how far have we come? Eur Heart J. 2015;36:1505-11.

5. Shinbane JS, Colletti PM, Shellock FG. Magnetic resonance imaging in patients with cardiac pacemakers: era of 'MR Conditional' designs. J Cardiovasc Magn Reson. 2011;13:63.

6. Wells GA, Shea B, O'Connell D, et al. The Newcastle-Ottawa Scale (NOS) for Assessing the Quality of Nonrandomised Studies in Meta-Analyses. http://www.ohri.ca/programs/clinical_epidemio logy/oxford.asp. Accessed: 2017

7. DerSimonian R, Laird N. Meta-analysis in clinical trials. Control Clin Trials. 1986;7:177-88.

8. Higgins JPT, Green S. Cochrane handbook for systematic reviews of interventions version 5.1.0 (updated March 2011). 2011.

9. Acha MR, Keaney JJ, Lubitz SA, et al. Increased perforation risk with an MRI-conditional pacing lead: a single-center study. Pacing Clin Electrophysiol. 2015;38:334-42.

10. Forleo GB, Santini L, Rocca DDG, et al. Safety and efficacy of a new magnetic resonance imaging-compatible pacing system: early results of a prospective comparison with conventional dualchamber implant outcomes. Heart Rhythm. 2010;7:750-4.

11. Rickard J, Taborsky M, Bello D, et al. Short- and long-term electrical performance of the 5086MRI pacing lead. Heart Rhythm. 2014;11:222-9.

12. Wollmann CG, Thudt K, Vock P, Globits S, Mayr H. Clinical routine implantation of a dual chamber pacemaker system designed for safe use with MRI: a single center, retrospective study on lead performance of Medtronic lead 5086MRI in comparison to Medtronic leads 4592-53 and 4092-58. Herzschrittmacherther Elektrophysiol. 2011;22:233-6, 9-42.

13. Kwon CH, Choi JH, Kim J, et al. Complications of cardiac perforation and lead dislodgement with an MRI-conditional pac- 
ing lead: a Korean multi-center experience. J Korean Med Sci. 2016;31:1397-402.

14. Wilkoff BL, Bello D, Taborsky M, et al. Magnetic resonance imaging in patients with a pacemaker system designed for the magnetic resonance environment. Heart Rhythm. 2011;8:65-73.
15. Gimbel JR, Bello D, Schmitt M, et al. Randomized trial of pacemaker and lead system for safe scanning at 1.5 Tesla. Heart Rhythm. 2013;10:685-91.

16. Healey JS, Krahn AD. Bad lead? Good lead? What should we believe? Heart Rhythm. 2009;6:210-1. 